\title{
Dual-Gate Organic Field-Effect Transistor for pH Sensors with Tunable Sensitivity
}

\author{
Raphael Pfattner, Amir M. Foudeh, Shucheng Chen, Weijun Niu, James R. Matthews, \\ Mingqian He, and Zhenan Bao*
}

Dual-gate field-effect transistors (FETs) based on organic semiconductor polymer and $\mathrm{SiO}_{x}$ as the topmost active sensing layer permit monitoring of $\mathrm{pH}$ in physiologically relevant conditions in a fast and reversible fashion. Beyond that, due to the bottom gate-induced field effect, such sensors exhibit tunable sensitivity and provide faster continuous measurements compared to conventional bulky glass bulb $\mathrm{pH}$ sensors. $\mathrm{pH}$ response of bare $\mathrm{SiO}_{x}$ is evaluated independently by means of voltmeter measurements. When assembled in dual-gate architecture, the $\mathrm{pH}$ response of FET devices scales in agreement with the theoretical model, which assumes capacitive coupling, exhibiting an amplification of up to 10. This opens up the possibility for reversible and reliable sensing based on organic semiconductors well beyond pH sensors.

\section{Introduction}

The concept of $\mathrm{pH}$, for measuring acidity and alkalinity, was first introduced by S. P. L. Sørensen back in 1909. ${ }^{[1]}$ Very thin, glass diaphragm-based electrodes for differential measurements ${ }^{[2]}$ and Beckmann's famous apparatus for testing acidity followed thereafter. ${ }^{[3]}$ A number of different techniques enabling $\mathrm{pH}$ detection including optical fiber, mass-sensitive devices, metaloxide transistor, conducting polymer, nanoconstructed cantilever, or even $\mathrm{pH}$ colorimetry, were reported. ${ }^{[4]}$ An important milestone for chemical- and biosensing applications was achieved in 1970 with the introduction of ion sensitive field-effect transistors (ISFETs) based on inorganic semiconductors. ${ }^{[5-7]}$

In sharp contrast to Si-based ISFETs, the transfer characteristics of graphene transistors are strongly dependent on the buffer composition of a $\mathrm{pH}$ solution ${ }^{[8]}$ and exhibit gate voltage shifts upon changing solution's $\mathrm{pH}$ level. However, stable and reversible $\mathrm{pH}$ sensing can be achieved by adding a $\mathrm{pH}$ sensitive

Dr. R. Pfattner, ${ }^{[+]}$Dr. A. M. Foudeh, S. Chen, Prof. Z. Bao

Department of Chemical Engineering

Stanford University

Stanford, CA 94305, USA

E-mail: zbao@stanford.edu

Dr. W. Niu, Dr. J. R. Matthews, Dr. M. He

Corning Incorporated

One River Front Plaza, Corning, NY 14831, USA

The ORCID identification number(s) for the author(s) of this article can be found under https://doi.org/10.1002/aelm.201800381.

${ }^{[+}$Present address: Institut de Ciència de Materials de Barcelona (ICMAB-CSIC), Campus de la UAB, 08193 Bellaterra, Spain

DOI: 10.1002/aelm.201800381 top dielectric layer. ${ }^{[9]}$ Similarly, water stability of organic semiconductor-based field-effect transistors has been shown earlier, and a current increase at different $\mathrm{pH}$ has been attributed to an increasing hydronium ion concentration which most likely diffuses into the transistor channel region. ${ }^{[10]}$ This topic is still under investigation, as shown in a recent report on ion uptake and its correlation to the performance of solution-gated transistors. ${ }^{[11]}$ One promising approach to exploit ionic diffusion is organic electrochemical transistor sensor where the electrically active semiconductor acts as an ion-to-electron transducer. ${ }^{[12,13]}$

It has been shown that stable device performance in pure water ${ }^{[14]}$ and reversible $\mathrm{pH}$ sensors can be realized by employing ion selective membranes in devices using organic semiconductors with geometries resembling ISFETs. ${ }^{[15]}$ However, similar structures are limited in stability due to Faradic leakage currents or electrolysis. To improve sensing stability, direct contact of either the electrodes or the semiconductor with electrolyte solution has to be avoided.[16] An interesting approach in this context are sensors based on extended gate architectures. ${ }^{[17-20]}$ Dual-gate device structure, on the other hand, has additional amplification in sensing as the change in drain-source current scales with the ratio of capacitance of the top gate over that of bottom gate. ${ }^{[16]}$

Electrical and chemical stability of the semiconductor is a crucial issue when aiming at sensor applications, and it is a necessary condition to enable reversible, stable, and drift-free sensors. Organic semiconducting polymers and small molecules used as electric-active materials in FETs have shown increasing stability and performance in recent years. ${ }^{[10,21-24]}$ Additionally, such materials enabling high tunability depending on the chemical design, biocompatibility, or even total disintegrability, have been reported recently. ${ }^{[25]}$

Here, we report reversible and stable $\mathrm{pH}$ sensors based on a solution processable semiconducting polymer and a $\mathrm{pH}$ active top dielectric in a dual-gate device configuration for fast and continuous measurements in physiologically relevant salt concentrations and $\mathrm{pH}$ values. ${ }^{[26]}$ In sharp contrast to typical ISFET device structures, the difference in this approach is that there is no external voltage applied to the electrolyte solution but a reference/ground electrode is electrically connected to the source electrode and is used to keep the electrolyte solution potential from drifting. Thus, externally induced electrical bias across the 
(a)
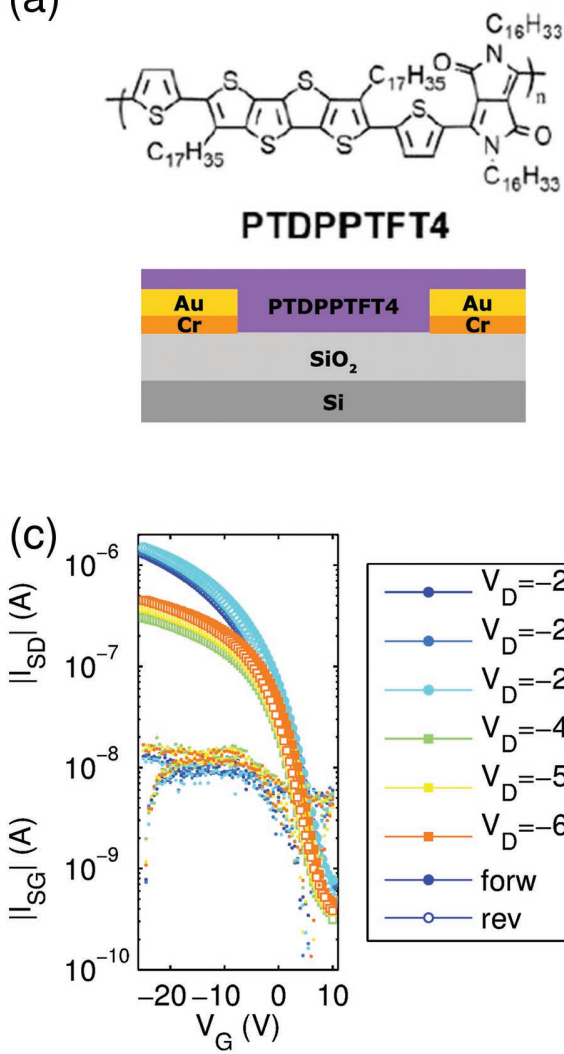
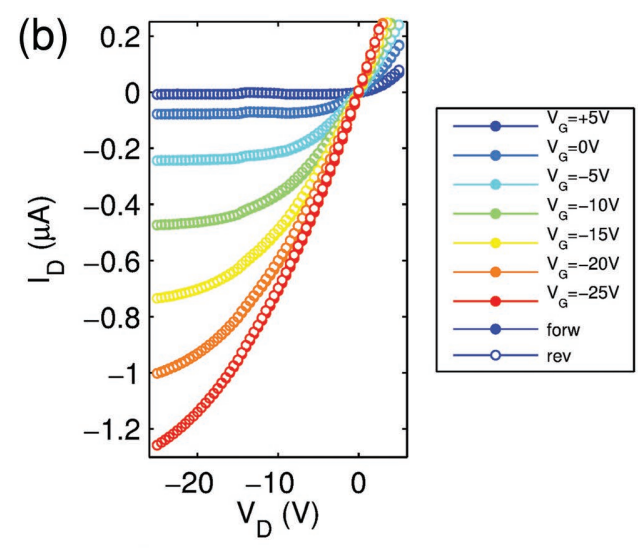

(d)
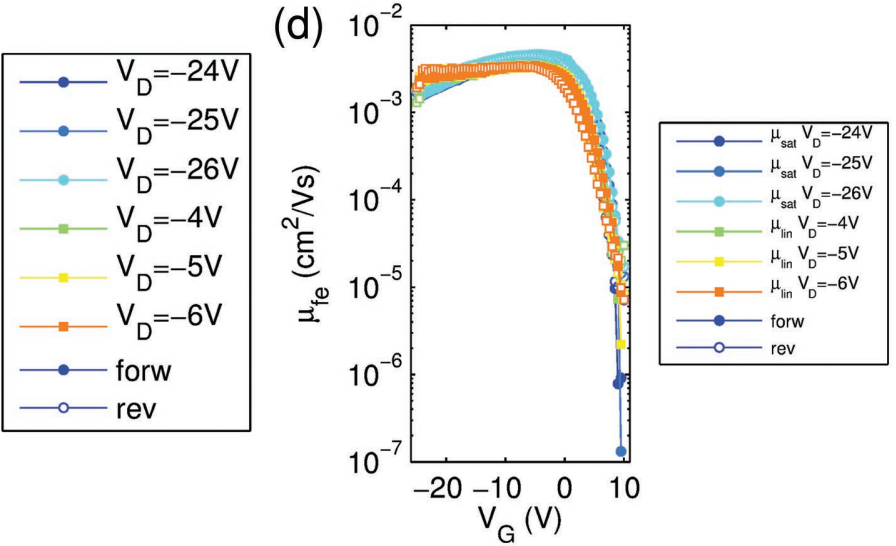

Figure 1. OFET device characteristics measured with the organic semiconductor directly exposed to ambient air. a) Chemical structure of PTDPPTFT4 used as semiconductor and bottom-gate bottom-contact device structure. b) The corresponding output characteristics for a device with channel length and width of 50 and $4000 \mu \mathrm{m}$, respectively. c) Transfer characteristics including leakage currents in both linear and saturation regimes. d) Gate voltage-dependent field-effect mobility extracted in both linear and saturation regimes. Closed and open symbols represent forward and reverse sweeps, respectively.

active sensing layer is significantly reduced, thereby enhancing device stability and sensitivity.

The biochemical importance of $\mathrm{pH}$ in living organisms is well-known in blood, where variations as little as $0.05 \mathrm{pH}$ units have a strong impact on the functioning of the human body. ${ }^{[27]}$ Except for gastric fluids which reach very acidic $\mathrm{pH}$ levels $(\mathrm{pH}$ about 2), typical values for bodily fluids, including blood, urine, saliva, tears, and sweat, range from $\mathrm{pH} 5$ to $8 .^{[28-30]}$

\section{Results and Discussions}

\subsection{Dual-Gate Field-Effect Transistor}

For the design of a stable, reversible, and drift-free doublegate FET-based $\mathrm{pH}$ sensor, two necessary requirements need to be met: i) a field-effect transistor with stable device characteristics and ii) a topmost layer with two functions, both high surface $\mathrm{pH}$ sensitivity as well as good encapsulation, ensuring that the organic semiconductor works in the field-effect regime preventing ion diffusion and chemical doping. Therefore, poly(tetrathienoacene-diketopyrrolopyrrole) (PTDPPTFT4) was chosen as the semiconductor in bottom-gate bottom-contact device geometry on a silicon wafer substrate with thermally grown $\mathrm{SiO}_{2}$ as bottom dielectric. For the top dielectric, thermally evaporated $\mathrm{SiO}_{x}$ has been chosen due to the presence of many hydroxyl groups on its surface and mild conditions of thermal evaporation.

Even though for top-contact device architectures higher device performance is typically achieved, ${ }^{[31,32]}$ for the current work, thermally evaporated $\mathrm{Cr} / \mathrm{Au}$ bottom-contact source and drain electrodes were chosen due to better mechanical stability and robustness in later measurements involving polydimethylsiloxane (PDMS) flow cells. All devices were prepared on highly doped n-type Si $(100)(\rho<0.004 \Omega \mathrm{cm})$ wafer pieces with $300 \mathrm{~nm}$ thermally grown $\mathrm{SiO}_{2}$ as the bottom dielectric layer. The semiconductor PTDPPTFT4 was spin-coated under inert conditions and vacuum annealed at $120^{\circ} \mathrm{C}$ for about $2 \mathrm{~h}$. Figure 1a shows the chemical structure of PTDPPTFT4 and the FET device geometry. Channel length and width of the devices were chosen to be $L=50 \mu \mathrm{m}$ and $\mathrm{W}=4000 \mu \mathrm{m}$, respectively. Electrical device characteristics measured under ambient conditions revealed almost textbook-like behavior with hardly any hysteresis observable neither in output nor transfer characteristics. The field-effect mobility was extracted both in the linear and the saturation regimes, employing various constant drain voltages with forward and reverse sweeps of gate voltage. Fieldeffect mobility was calculated after linearization of the drain 
(a)

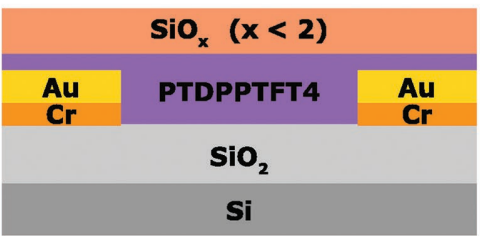

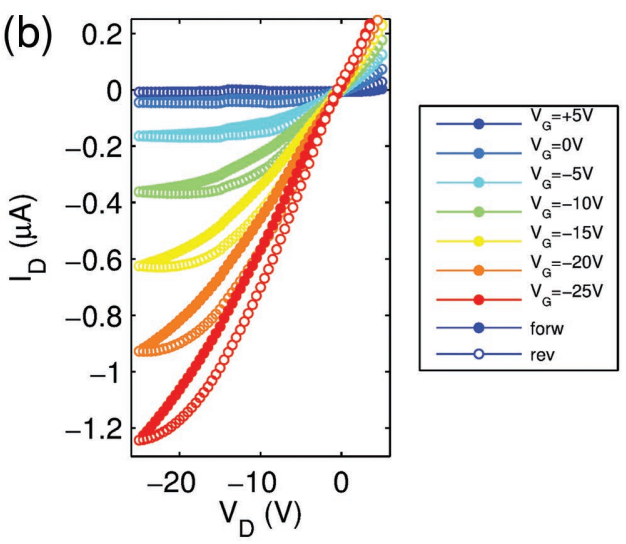

(d)

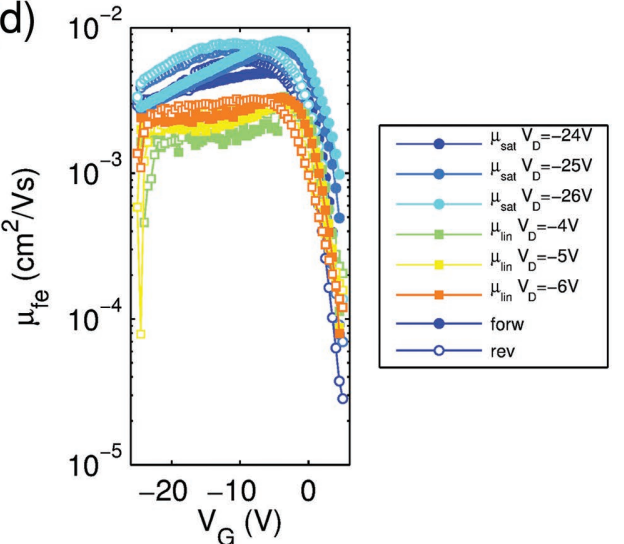

Figure 2. OFET device characteristics with thermally evaporated $\mathrm{SiO}_{x}$ top layer measured in ambient air. a) Chemical structure of PTDPPTFT4 used as semiconductor and bottom-gate bottom-contact device structure with topmost thermally evaporated $50 \mathrm{~nm} \mathrm{SiO}_{x}$ layer. b) The corresponding output characteristics for a device with channel length and width of 50 and $4000 \mu \mathrm{m}$, respectively. The thermally grown $\mathrm{SiO}_{2}$ gate dielectric is $300 \mathrm{~nm}$ in thickness. c) Transfer characteristics including leakage currents in both linear and saturation regimes. d) Gate voltage-dependent field-effect mobility extracted in both linear and saturation regime. Closed and open symbols represent forward and reverse sweeps, respectively.

current and performing a linear fit, leading to $\mu_{\text {lin }}=0.0124 \pm$ $0.0003 \mathrm{~cm}^{2} \mathrm{~V}^{-1} \mathrm{~s}^{-1}$ and $\mu_{\text {sat }}=0.014 \pm 0.001 \mathrm{~cm}^{2} \mathrm{~V}^{-1} \mathrm{~s}^{-1}$, linear and saturation regimes, respectively. Threshold voltage was extracted to be $V_{\text {th,lin }}=2.2 \pm 0.9 \mathrm{~V}$ and $V_{\text {th,sat }}=5.6 \pm 0.8 \mathrm{~V}$, linear and saturation regimes, respectively (see also Section S1 in the Supporting Information). All extracted values employing different drain voltages in the transfer characteristics are within a very narrow window and well in agreement with the output characteristics.

Even though the organic semiconductor was deposited under inert atmosphere and vacuum annealed, the slightly positive $V_{\text {th }}$ can be attributed to unintentional doping at the $\mathrm{SiO}_{2} /$ PTDPPTFT4 interface. As clearly observable in Figure 1d, which shows the gate-voltage dependence of the calculated field-effect mobilities, all curves overlap and show very similar gate voltage dependence as well as a narrow and steep increase close to the extracted $V_{\text {th. }}$.

The second step of device fabrication consists of depositing the top-dielectric layer where silicon monoxide ( $\mathrm{SiO}$ ) has been chosen and was thermally evaporated on top of prepared FET devices using a shadow mask to keep electrical access to the source and drain electrodes. Figure 2a shows the encapsulated FET device structure. In order to study thermal evaporation effects and possible substrate heating on the FET performance, devices have been electrically characterized again shortly after
$50 \mathrm{~nm} \mathrm{SiO}_{x}$ deposition and measured under ambient conditions. Figure $2 \mathrm{~b}$ shows the output characteristics, exhibiting similar on-currents compared to devices measured before encapsulation, but with a clear positive hysteresis, which may be attributed to the hygroscopic nature of thermally evaporated $\mathrm{SiO}_{x} \cdot{ }^{[33]}$ Although we cannot completely rule out the creation of traps during the thermal deposition of $\mathrm{SiO}_{x}$, we decided to study the hygroscopic nature of $\mathrm{SiO}_{x}$ by monitoring the thickness of freshly prepared $\mathrm{SiO}_{x}$ upon exposure to nitrogen and ambient air. A clear increase in apparent thickness was found. Once the vacuum was restored in the chamber, the thickness was partially recovered (see Figure S14 in the Supporting Information).

Similar to the first fabrication step, field-effect mobility was calculated, leading to $\mu_{\text {lin }}=0.0098 \pm 0.0015 \mathrm{~cm}^{2} \mathrm{~V}^{-1} \mathrm{~s}^{-1}$ and $\mu_{\mathrm{sat}}=0.022 \pm 0.004 \mathrm{~cm}^{2} \mathrm{~V}^{-1} \mathrm{~s}^{-1}$, linear and saturation regimes, respectively. The threshold voltage was extracted to be $V_{\text {th,lin }}=2.3 \pm 1.5 \mathrm{~V}$ and $V_{\text {th,sat }}=4.0 \pm 1.6 \mathrm{~V}$, linear and saturation regimes, respectively (see also Section S2 in the Supporting Information). Figure $2 \mathrm{~d}$ shows the gate voltage dependence after $50 \mathrm{~nm}$ of thermal $\mathrm{SiO}_{x}$ deposition. Slightly lower mobility and threshold voltage values are in agreement with dedoping of the organic semiconductor, but very similar characteristics were found compared to devices measured without encapsulation. 
Importantly, as shown in Figure 2d, driving the devices in the linear operation regime leads to very similar mobility and threshold voltage values as well as almost no gate-voltage dependence of the mobility. This is not surprising and in fact thermally evaporated $\mathrm{SiO}_{x}$ has been used previously for the preparation of optical coatings ${ }^{[34-36]}$ and electrical encapsulation to enable stable n-channel transport in FETs. ${ }^{[37,38]}$ Employing higher drain bias, i.e., in the saturation regime, slightly higher mobility values have been extracted, but also a stronger mobility gate-voltage dependence was observed which is also reflected in the larger mobility standard deviation.

These findings are important for the design and for the establishment of the working point, i.e., voltage bias, of stable, drift-free, and fully reversible sensors. In summary, no significant electrical device degradation was found upon $\mathrm{SiO}_{x}$ deposition and small indications toward the sensing capability of $\mathrm{SiO}_{x}$ as an active surface were encountered.

\subsection{Silicon Monoxide as $\mathrm{pH}$ Active Sensing Layer}

$\mathrm{SiO}$ is a chemical compound where silicon is present in the oxidation state +2 , a diatomic molecule in vapor phase. It has been detected in stellar objects and it has been described as the most common oxide of silicon in the universe. ${ }^{[39]} \mathrm{SiO}$ is a well-characterized molecule at high temperatures and all known morphologies of solid $\mathrm{SiO}$ are amorphous. Silicon atoms in solid $\mathrm{SiO}$ are tetrahedrally coordinated, which implies that the structure of $\mathrm{SiO}$ is composed of 5 structural units, i.e., $\mathrm{Si}\left(\mathrm{Si}_{4-x} \mathrm{O}_{x}\right)$ with $(x=0-4)$. The stoichiometry of $\mathrm{SiO}$ requires as a side condition that $50 \%$ of the bonds must be $\mathrm{Si}-\mathrm{Si}$ and $50 \% \mathrm{SiO}$. Various models differ in the proportion and distribution of the different units. ${ }^{[39]} \mathrm{SiO}$ and $\mathrm{SiO}_{2}$ are the simplest binary compounds of silicon and oxygen, which are the most abundant elements in the earth's crust. ${ }^{[40,41]}$ However, to obtain highly pure $\mathrm{SiO}_{2}$, i.e., fabrication of thermally grown $\mathrm{SiO}_{2}$ in wafer production, high temperatures and oxygen atmosphere are needed. In contrast to that, as shown in recent reports, thermal evaporation of $\mathrm{SiO}$ on highly oriented pyrolytic graphite (HOPG) with the substrate at room temperature leads to the formation of $\mathrm{SiO}_{x}$ with $1<x<2$ once exposed to ambient air. ${ }^{[42]}$ Comparing the X-ray photoelectron spectroscopy (XPS) spectra of thermally grown $300 \mathrm{~nm} \mathrm{SiO}_{2}$ and our thermally evaporated $50 \mathrm{~nm} \mathrm{SiO}_{x}$, both $\mathrm{O} 1 \mathrm{~s}$ lines and $\mathrm{Si} 2 \mathrm{p}$ lines show a shift to lower binding energies and are in agreement with literature data (see Section S3.2 in the Supporting Information) ${ }^{[43]}$

$\mathrm{pH}$ sensitivities of oxides have been reported earlier and theoretically described by the oxide site binding model. ${ }^{[44-47]}$ The electrolyte- $\mathrm{SiO}_{x}-\mathrm{Si}$ interfaces have also been studied in more detail at different $\mathrm{pH}$ conditions. ${ }^{[48]}$ Therefore, with the aim to characterize the $\mathrm{pH}$ sensitivity of our thermally evaporated $\mathrm{SiO}_{x}$, a $\mathrm{Cr} / \mathrm{Au}$ electrode was deposited on a glass slide and $50 \mathrm{~nm}$ of $\mathrm{SiO}_{x}$ was deposited using a shadow mask to keep the bottom electrode electrically accessible. On top of this structure, a PDMS chamber was mounted including a Pt ground electrode. With the help of this flow cell, the surface of $\mathrm{SiO}_{x}$ was exposed to solutions with different $\mathrm{pH}$ values, as shown schematically in Figure 3a. phosphate-buffered saline (PBS) $1 \times$ was used as starting solution and $\mathrm{pH}$ was modified by adding $\mathrm{HCl}$ or $\mathrm{NaOH}$ ranging from $2.4 \pm 0.1$ to $11.7 \pm 0.1$ with an electrical conductivity of about $\sigma=13.8 \pm 0.5 \mathrm{mS} \mathrm{cm}^{-1}$. As control solutions, $\mathrm{NaCl}$ was dissolved in deionized (DI) water at concentrations ranging from $1 \times 10^{-3}$ to $140 \times 10^{-3} \mathrm{M}$ with the corresponding $\mathrm{pH}$ value of about $7.3 \pm 0.1$ (see Section S3 in the Supporting Information). To guarantee the supply of fresh $\mathrm{pH}$ solutions inside the flow cell, a flow rate of $0.5 \mathrm{~mL} \mathrm{~min}{ }^{-1}$ was established. From an electrical point of view, this set of solutions exhibits a broad window of both conductivity and $\mathrm{pH}$, thus covering the properties of most physiological liquids. ${ }^{[26]}$ To electrically measure the potential of the $\mathrm{SiO}_{x} /$ electrolyte-solution interface, a Keithley 2635A Source Meter, with high input impedance of $10^{14} \Omega$, was connected in voltmeter configuration with the Pt electrode set to instrument ground. Figure $3 \mathrm{~b}$ shows the $\mathrm{pH}$ response of the $\mathrm{SiO}_{x}$ surface measured by monitoring the voltage. After stabilization, the mean value and standard deviation of the measured voltage were determined from 10 points. Typical parasitic currents measured in this device structure were found to be of the order of $100 \mathrm{fA}$, which is very low. This suggests a correctly working measurement of the electrical potential and is an indication of homogeneous coverage with $\mathrm{SiO}_{x}$. This experiment has been carried out by testing a variety of solutions, including $\mathrm{pH}$ values of $\mathrm{pH}: 2.4 \pm 0.1,3.4 \pm 0.1,6.1 \pm 0.1$, $7.3 \pm 0.1,8.0 \pm 0.1$, and $11.7 \pm 0.1$, as well as running continuous cycles for up to $50 \mathrm{~min}$. The estimated surface $\mathrm{pH}$ sensitivity of $\mathrm{SiO}_{x}$ was found to be $S_{\mathrm{V}, \mathrm{pH}}=-41 \pm 7 \mathrm{mV}$ per $\mathrm{pH}$ with response linearity of about $R^{2}=0.98 \pm 0.01$. Small $\mathrm{pH}$ variations of only $\Delta \mathrm{pH}=0.8 \pm 0.1$ exhibited fast and reversible voltage response with a sensitivity of $S_{\mathrm{V}, \mathrm{pH}}=-45 \pm 7 \mathrm{mV}$ per $\mathrm{pH}$ (see also Section S3.4 in the Supporting Information). In order to analyze $\mathrm{pH}$ response and stability of $\mathrm{SiO}_{x}$ further, a second device architecture including $100 \mathrm{~nm}$ of $\mathrm{SiO}_{x}$ deposited directly on top of PTDPPTFT4 was studied. Stability and voltage response with devices in solutions at $\mathrm{pH}: 7.3 \pm 0.1$ and $\mathrm{pH}$ : $4.0 \pm 0.1$ under continuous exposure for up to $48 \mathrm{~h}$ were measured (Figure 3e). The corresponding $\mathrm{pH}$ sensitivity extracted for 17 consecutive cycles was found to be $S_{\mathrm{V}, \mathrm{pH}}=-40 \pm 8 \mathrm{mV}$ per $\mathrm{pH}$.

These findings and $\mathrm{pH}$ sensitivity are close to the Nernst limit ${ }^{[49,50]}$ and in good agreement with literature values, where different glass surfaces have been studied for $\mathrm{pH}$ response ranging from Pyrex glass $(18 \mathrm{mV}$ per $\mathrm{pH})$ to Corning 015 glass $(59 \mathrm{mV}$ per $\mathrm{pH}) \cdot{ }^{[33,51]}$ In addition to high sensitivity, we also observed fast and reversible responses with high linearity, important for sensors because they are compatible with typically used two or three point calibration protocols.

In order to study stability of the thermally evaporated $\mathrm{SiO}_{x}$, two sets of samples with 50 and $250 \mathrm{~nm}$ thicknesses were prepared and exposed to different solutions at $\mathrm{pH}$ levels of $\mathrm{pH}$ $7.3 \pm 0.1, \mathrm{pH} 2.7 \pm 0.1$, and $\mathrm{pH} 11.5 \pm 0.1$ for up to $15 \mathrm{~h}$. The thickness was monitored by profilometer, exhibiting negligible degradation effects in the measured time frame (Figure $3 \mathrm{~g}$ ). Morphology has been characterized by means of atomic force microscopy, exhibiting homogeneous films with low surface roughness of about root mean square (RMS) $=0.73 \mathrm{~nm}$ (see Section S3.3 in the Supporting Information).

In summary, the voltmeter setup turned out to be a simple and reliable technique to characterize the sensitivity of the active layer (i.e., $\mathrm{SiO}_{x}$ ) by following its voltage $\mathrm{pH}$ response. Continuous measurements of this type on $\mathrm{pH}$ sensitivity and 
(a)

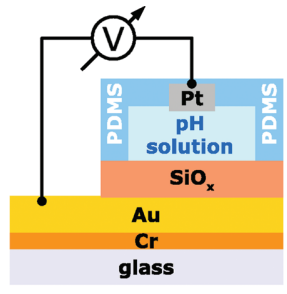

(d)

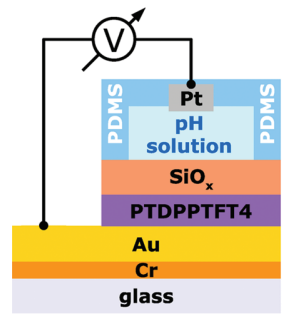

(b)

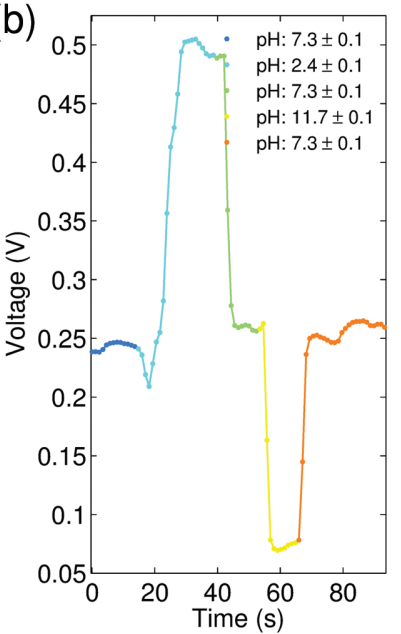

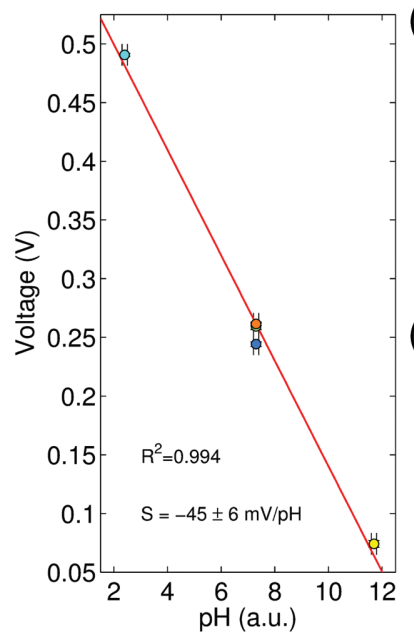

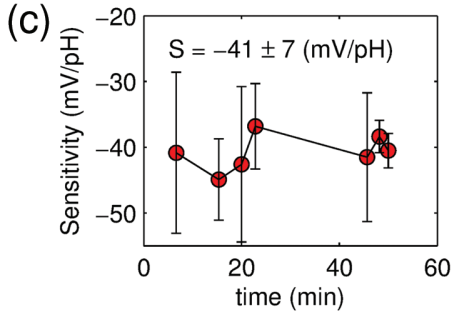

(f)

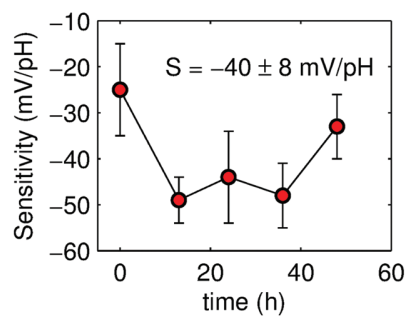

(e)

as prepared

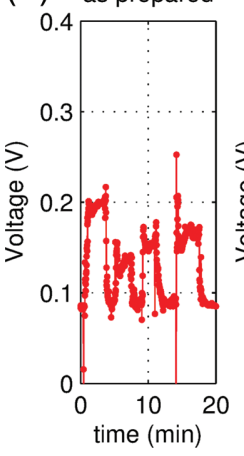

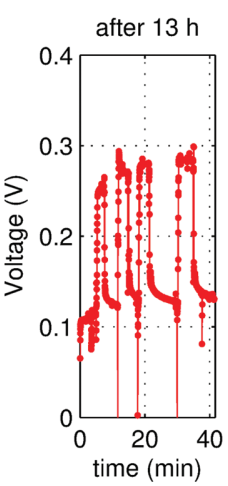
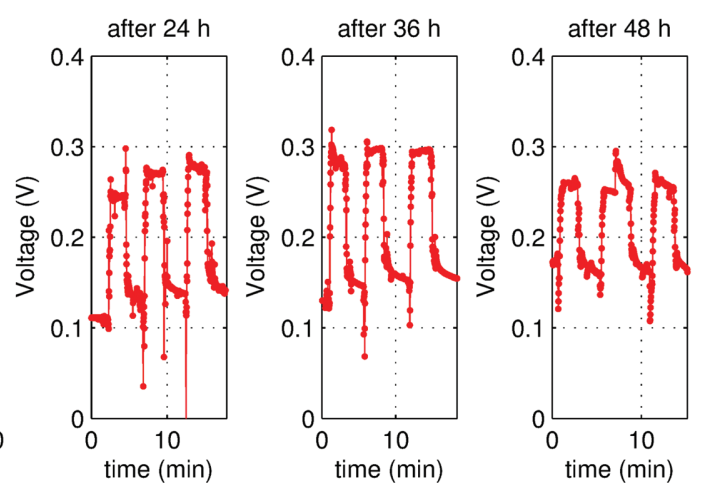

(g)

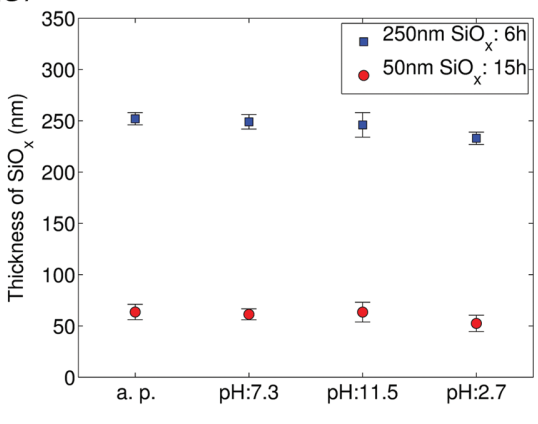

Figure 3. Electrical characterization and stability of $\mathrm{pH}$ active $\mathrm{SiO}_{x}$. a) Device structure with topmost thermally evaporated $50 \mathrm{~nm} \mathrm{SiO}$ layer on top of $\mathrm{Au}$ directly exposed to modified PBS solution at different $\mathrm{pH}$ and schematic representation of voltmeter setup. b) Time series of voltage response with $\mathrm{SiO}_{x}$ exposed to different $\mathrm{pH}$ values with extraction of $\mathrm{pH}$ sensitivity using linear regression. $\mathrm{c}$ ) The corresponding $\mathrm{pH}$ sensitivity $\left(50 \mathrm{~nm} \mathrm{SiO}_{x}\right)$ extracted for 18 consecutive cycles and values of $\mathrm{pH}: 2.4 \pm 0.1,3.4 \pm 0.1,6.1 \pm 0.1,7.3 \pm 0.1,8.0 \pm 0.1$, and $11.7 \pm 0.1$, in total lasting for about 50 min. d) Device structure with topmost thermally evaporated $100 \mathrm{~nm} \mathrm{SiO}$ on PTDPPTFT4. e) The corresponding stability and voltage response with device in solutions at $\mathrm{pH}: 7.3 \pm 0.1$ and $\mathrm{pH}: 4.0 \pm 0.1$ under continuous exposure for up to $48 \mathrm{~h}$. f) The corresponding pH sensitivity (100 nm $\mathrm{SiO}_{x}$ ) extracted for 17 consecutive cycles. g) Thickness dependence of thermally evaporated $\mathrm{SiO}_{x}$ upon storage in solutions at different $\mathrm{pH}$.

stability of $\mathrm{SiO}_{x}$ have not been reported in previous literature. As reflected by very low parasitic currents, $\mathrm{SiO}_{x}$ successfully combines tight encapsulation with high $\mathrm{pH}$ surface sensitivity.

\subsection{Dual-Gate Field-Effect Transistor as $\mathrm{pH}$ Sensor}

After characterizing the sensitivity of the thermally evaporated $\mathrm{SiO}_{x}$ with a voltmeter setup, the device performance in a dual-gate field-effect transistor was investigated. In a dual-gate field-effect transistor, the semiconducting layer is sandwiched/ encapsulated between two gate dielectrics. This structure has been reported previously to control the threshold voltage in devices for integrated circuits, ${ }^{[52,53]}$ but more interestingly, to enhance the sensitivity of sensors. ${ }^{[16,54,55]}$ Depending on the ratio between top capacitance to bottom capacitance $\left(C_{\text {top }} / C_{\text {bottom }}\right)$, an amplification ratio has been shown. ${ }^{[16]} \mathrm{SiO}_{x}$ has been successfully used as the top-gate dielectric in double-gate graphene field-effect transistors to shift the Dirac point voltage. ${ }^{[56]} \mathrm{pH}$ sensors based on different oxide dielectrics and solution-gated field-effect transistors have been reported earlier. ${ }^{[57]}$
Previously, we found that when the organic semiconductor is directly exposed to the electrolyte solution, a clear increase of $I_{\mathrm{D}}$ at high $\mathrm{pH}$ and a clear decrease of $I_{\mathrm{D}}$ at low $\mathrm{pH}$ are in agreement with electrostatic coupling of the electrolyte solution and the transistor channel (p-channel operation). However, there was an important overall decrease of $I_{\mathrm{D}}$ which is most probably related to a slight degradation of PTDPPTFT4 under harsh acidic conditions. This was observed even though the device was driven at very low voltages (constant $V_{\mathrm{D}}=-0.1 \mathrm{~V}$ and $\left.V_{\mathrm{G}}=-0.3 \mathrm{~V}\right) .{ }^{[58]}$ Therefore, an additional topmost $\mathrm{SiO}_{x}$ layer could potentially improve device stability and sensitivity.

In order to investigate if our device structure can be used as a reliable $\mathrm{pH}$ sensor, a PDMS flow cell containing a Pt ground electrode was mounted on top of the double-gate FET. It is important to highlight here that in sharp contrast to previously reported solution-gated structures, the Pt electrode was used to connect the electrolyte solution to ground, thus preventing it from electrostatic drifting, and no external voltage bias was applied to the Pt electrode. This in fact is part of the novelty of the current approach, because in this configuration, the potential change at the $\mathrm{SiO}_{x} /$ electrolyte-solution interface is the 


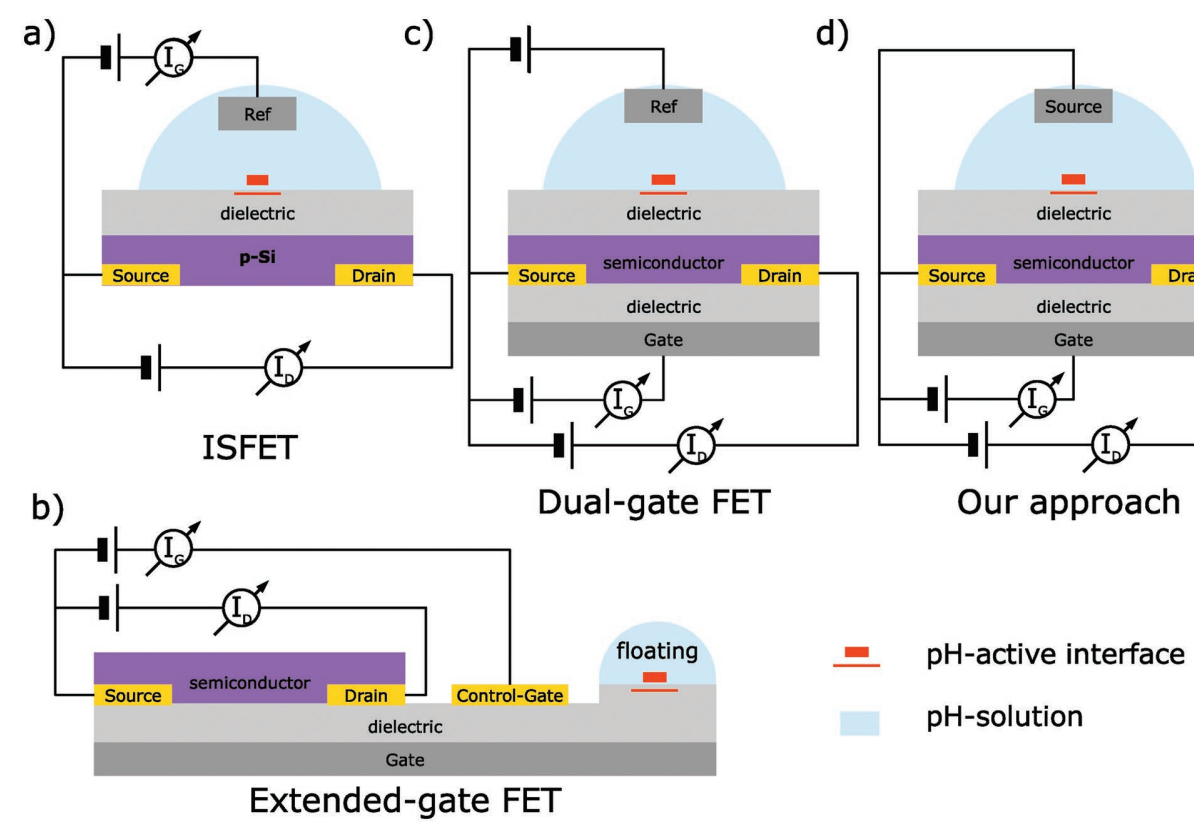

Figure 4. Schematic, simplified representation of FET-based pH sensors in different bias configurations. a) Conventional ISFET, where gate voltage is applied in series with $\mathrm{pH}$ active interface. ${ }^{\left[{ }^{[}\right]}$b) Extended-gate FET where the working point of the transistor is controlled via control gate; sensing is done at extended floating gate with no reference electrode. ${ }^{[17]} \mathrm{c}$ ) Most general dual-gate FET structure with both top and bottom gates, both suitable to control the working point of the transistor. $\left.{ }^{[16]} \mathrm{d}\right)$ Special type of dual-gate FET with reference electrode, or pseudo-reference electrode directly connected to source (GND) (this work).

only voltage source in case of a sensing event. Thus, allowing a complete decoupling between control voltage (i.e., bottom-gate voltage used to tune the working point of the FET) and sensing voltage (i.e., voltage drop across the active sensing layer). Different FET-based sensors with bias conditions are compared in Figure 4 including: a) conventional ISFET geometry, ${ }^{[5]}$ b) Extended-gate FET, ${ }^{[17]}$ c) general structure of a dual-gate FET proposed by Spijkman et al., ${ }^{[16]}$ and d) a special type of dualgate FET used in this work.

A detailed device structure and electrical setup used in this work is schematically shown in Figure 5a. The transistor was driven at a constant drain and gate bias of $V_{\mathrm{D}}=-0.5 \mathrm{~V}$ and $V_{\mathrm{G}}=-5 \mathrm{~V}$, respectively, well within the linear operation regime of the device, but close to $V_{\text {th }}$ where FETs exhibit the highest sensitivity, i.e., subthreshold slope. Figure $5 \mathrm{~b}$ shows both drain current $\left(\left|I_{\mathrm{D}}\right|\right)$ and gate-leakage current $\left(\left|I_{\mathrm{G}}\right|\right)$ as functions of solutions with different $\mathrm{pH}$ values of: $2.8 \pm 0.1 ; 7.4 \pm 0.1 ; 11.2 \pm 0.1$. Fully reversible and fast responses to $\mathrm{pH}$ are clearly visible with negligible changes in the gate-leakage current.

The sensor response was defined as $\left(I_{\mathrm{D}, \mathrm{pH}}-I_{\mathrm{D}, \mathrm{ref}}\right) / I_{\mathrm{D}, \mathrm{ref}}$, in which $I_{\mathrm{D} \text {,ref }}$ and $I_{\mathrm{D}, \mathrm{pH}}$ were defined by taking the mean value including standard deviation of $I_{\mathrm{D}}$ consisting of 25 points at $\mathrm{pH}$ level of $7.4 \pm 0.1$ and the solution of interest. Figure $5 \mathrm{c}$ shows the response of two FET devices measured at different $\mathrm{pH}$ levels. For $\mathrm{pH}$ ranges from 5 to about 11, a linear response with good linearity of about 0.996 and high sensitivity of about $39 \pm 2 \%$ per $\mathrm{pH}$ was extracted. The error value of $2 \%$ per $\mathrm{pH}$ includes both standard deviation and signal reversibility and translates to a sensor resolution of $\Delta \mathrm{pH}= \pm 0.02$. Other structures shown in literature exhibited higher sensitivity but often also much higher error and signal noise. ${ }^{[17,59]}$ On the other hand, at $\mathrm{pH}$ levels below $\mathrm{pH} 5$, the response clearly deviates from linear dependence and flattens out, and eventually becomes independent of $\mathrm{pH}$. We hypothesize that the $\mathrm{H}_{3} \mathrm{O}^{+}$ concentrations at the $\mathrm{SiO}_{x}$ surface are high enough to induce a positive surface charge and an electric field in the transistor channel that switches the transistor channel off. This hypothesis agrees well with a constant transconductance $\left(\partial I_{\mathrm{D}} / \partial V_{\mathrm{G}}\right)$ of the device at $V_{\mathrm{D}}=-0.5 \mathrm{~V}$ and $V_{\mathrm{G}}<-1 \mathrm{~V}$. At more positive gate voltages $\left(-1 \mathrm{~V}<V_{\mathrm{G}}\right), \partial I_{\mathrm{D}} / \partial V_{\mathrm{G}}$ starts to decrease, thus deviating from the linear operation regime (see Figure S26 in the Supporting Information). The same effect is also observable in the gate voltage-dependent mobility shown in Figure $2 \mathrm{~d}$. To compare the device response in aqueous media other than PBS $1 \times$, device 3 (see Figure S23 in the Supporting Information) was exposed to different concentrations of $\mathrm{NaCl}$ in DI water with $\mathrm{pH} 7.3 \pm 0.1$ and electrical conductivity ranging from $\sigma=0.15 \pm 0.50 \mathrm{mS} \mathrm{cm}^{-1}$ to $\sigma=13.05 \pm 0.50 \mathrm{mS} \mathrm{cm}^{-1}$, leading to similar response values as reported above, showing a clear advantage compared to solution-gated structures, which are strongly dependent on the electrolyte conductivity. ${ }^{[11]}$

The working point of the double-gate structure has been chosen at $V_{D}=-0.5 \mathrm{~V}$ and $V_{G}=-5 \mathrm{~V}$, where the sensor is able to respond linearly to $\mathrm{pH}$ values higher than 5 , well in agreement with physiologically relevant conditions. This finding allows for tuning the linear working range of the FET. The closer the working point to the threshold voltage of the device, the higher the sensitivity. Similar findings, i.e., gate-voltage dependence of the sensitivity, have been reported earlier for inorganic Si-based $\mathrm{pH}$ sensors, which clearly work in the field-effect regime. ${ }^{60]}$

To clarify this dependence in our structure, FETs driven at different gate voltages have been tested. They showed decreasing sensitivity with increasing gate voltage, as well as decreasing sensitivity with gate dielectric thickness. This is in 
(a)

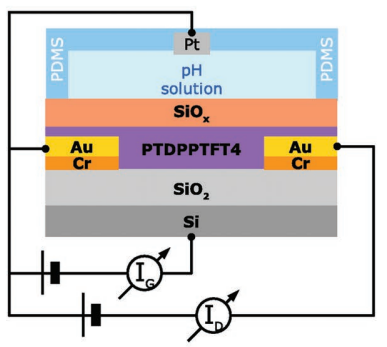

(c)

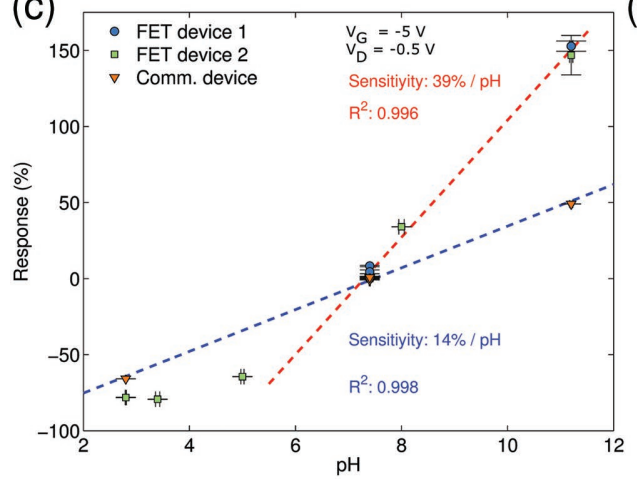

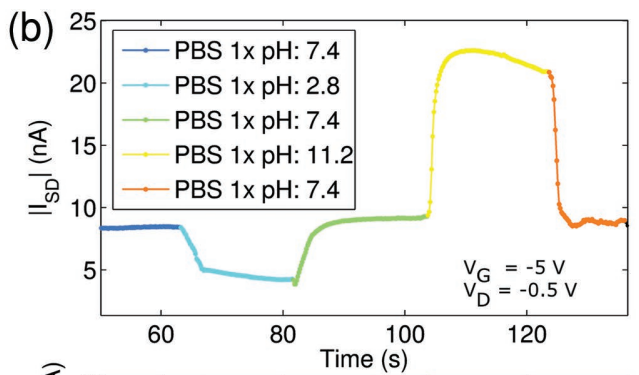

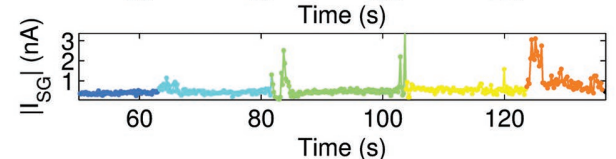

(d)

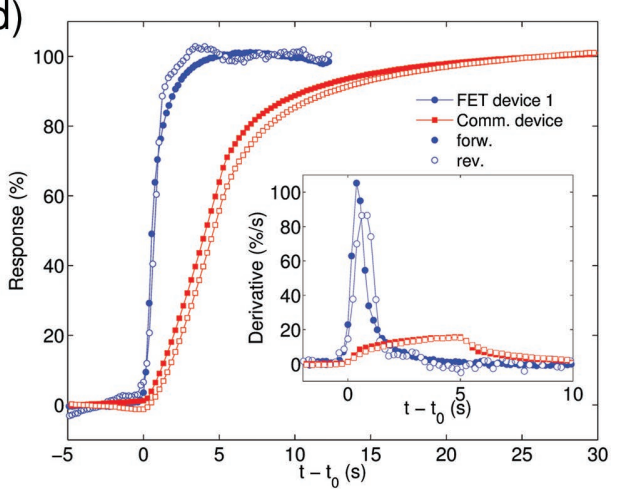

Figure 5. $\mathrm{pH}$ sensor based on dual-gate FET and $\mathrm{SiO}_{x}$ as the active sensing layer. a) Schematic representation of the device structure and electrical FET connections with topmost thermally evaporated $50 \mathrm{~nm} \mathrm{SiO}$ layer directly exposed to solution at different $\mathrm{pH}$. b) Typical drain current $\left(I_{\mathrm{D}}\right)$ response of dual-gate FET when exposed to solutions at different $\mathrm{pH}$ with the corresponding gate-leakage current. c) $\mathrm{pH}$-response of two dual-gate $\mathrm{FET}$ devices compared to commercial glass bulb sensor. d) Normalized response upon exposure to $\mathrm{pH} 11.2 \pm 0.1$ for both FET and commercial devices with response speed shown in the inset. Open and closed symbols correspond to switching solution to high pH (11.2 \pm 0.1$)$ and back to neutral pH $(7.4 \pm 0.1)$, respectively.

agreement with similar structures reported in literature (see also Figure S27 in the Supporting Information). ${ }^{[16]}$

As mentioned earlier, the amplification gain of similar structures depends on the capacitive coupling between top and bottom dielectric, defined as $C_{\text {top }} / C_{\text {bottom. }}{ }^{[16]}$ For the bottom dielectric, a capacitance of $C_{\mathrm{i} \text {,bottom }}=11.51 \pm 0.30 \mathrm{nF} \mathrm{cm} \mathrm{cm}^{-2}$ was measured, while for the top dielectric, a capacitance of about

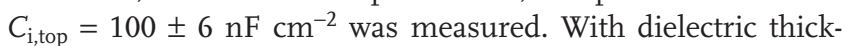
nesses of $d_{\mathrm{SiO} 2}=300 \pm 5 \mathrm{~nm}$ and $d_{\mathrm{SiO} x}=50 \pm 5 \mathrm{~nm}$, for bottom and top, respectively, material relative permittivities calculate to $\varepsilon_{\mathrm{r}, \mathrm{SiO} 2}=3.89 \pm 0.10$ and $\varepsilon_{\mathrm{r}, \mathrm{SiO} x}=5.7 \pm 0.9$ and are well in agreement with literature. ${ }^{[56]}$ Thus, the expected amplification is about $8.7 \pm 0.7$.

By comparing both the $\mathrm{pH}$ sensitivity measured in the voltmeter setup (Figure 3), and the current sensitivity at different $\mathrm{pH}$ levels with the transconductance of the device, a total amplification of: gain $=10 \pm 3$ was extracted, and is in good agreement with the amplification value found above (see Section S4.1 in the Supporting Information for extended calculations). These findings confirm potential tunability of our double-gate sensor through device structure engineering.

With the aim to benchmark our sensing platform with glass bulb $\mathrm{pH}$ sensors, a commercial $\mathrm{pH}$ sensor was connected to an Arduino Nano board used to electronically monitor the $\mathrm{pH}$ changes of different $\mathrm{pH}$ solutions. Between the $\mathrm{pH}$ electrode and the ADC converter of Arduino Nano, a silicon-based instrument amplifier was connected to tune the incoming signal matching 0-5 V level input of the analog-to-digital converter (ADC) (Figure S24, Supporting Information). Time series were measured and are reported in Figure S25 (Supporting Information). Figure $5 \mathrm{c}$ shows the comparison between the commercial $\mathrm{pH}$ sensor and our $\mathrm{pH}$ sensor, showing that the organic field-effect transistor (OFET)-based double-gate structure is about 2.8 times more sensitive than the commercial sensor. In comparison to that, recently published $\mathrm{IrO}_{x}$-gated electrochemical transistor sensors exhibit typical sensitivities of about $22 \%$ per $\mathrm{pH} .{ }^{[13]}$

Figure $5 \mathrm{~d}$ shows the normalized response to $\mathrm{pH}$ and its time derivative, exhibiting high and reversible values of up to $100 \% \mathrm{~s}^{-1}$ compared to $15 \% \mathrm{~s}^{-1}$ for double-gate FET and commercial sensor, respectively. Closed symbols correspond to switching the solution to high $\mathrm{pH} 11.2 \pm 0.1$, while open symbols represent backward change to $\mathrm{pH} 7.4 \pm 0.1$. Comparing both response speeds, this calculates to about 6.6 times faster response of our double-gate FET structure compared to the commercial glass bulb $\mathrm{pH}$ sensor. This is not surprising considering the fact that the active sensing surface of the glass bulb is about $0.7 \mathrm{~cm}^{2}$, which is much bigger than the active sensing area of the FET device, i.e., $W \times L=0.2 \mathrm{~mm}^{2}$.

In summary, the developed double-gate FET platform exhibited fast, reversible, and stable responses to $\mathrm{pH}$ with sensitivity of up to $39 \%$ per $\mathrm{pH}$ and resolution of $\Delta \mathrm{pH}_{\mathrm{FET}}= \pm 0.02$. 


\section{Conclusion}

OFETs based on the semiconducting polymer PTDPPTFT4 exhibited almost ideal device characteristics on $\mathrm{SiO}_{2}$ dielectric with very narrow variations in field-effect mobility extracted in both linear and saturation regimes as well as at different drain voltage bias. Furthermore, the $\mathrm{pH}$ sensitivity of thermally evaporated $\mathrm{SiO}_{x}$ was characterized independently using a voltmeter and exhibited both thickness- and substrate-independent high values of $S_{\mathrm{V}, \mathrm{pH}}=-41 \pm 7 \mathrm{mV}$ per $\mathrm{pH}$. Finally, combining $\mathrm{SiO}_{x}$ with the PTDPPTFT4 FET device in doublegate architecture gave fast and reversible responses to $\mathrm{pH}$, well in agreement with the established theoretical model, achieving amplification factor of about 10 times calculated using two different approaches. The key novelty of the present structure is on one hand the good encapsulation of the organic semiconductor by a top dielectric, which allows the device to operate in the field-effect regime rather than the electrochemical doping regime. On the other hand, the usage of a platinum electrode grounding the electrolyte solution, without applying an external voltage as it is usually done in solution-gated structures, keeps the electrolyte solution potential from drifting, significantly reducing the total electrical bias across the active sensing layer, allowing to decouple FET control voltage from sensing voltage. These findings contribute to considerably increased device stability and reversibility and pave the way toward promising sensing applications well beyond $\mathrm{pH}$ sensors.

\section{Experimental Section}

Materials and Device Preparation: Highly doped n-type Si (100, $\rho<0.004 \Omega \mathrm{cm}$ ) substrates with $300 \pm 5 \mathrm{~nm}$ thermally grown $\mathrm{SiO}_{2}$ were used to fabricate bottom-gate FET devices. Glass substrates were used for the fabrication of devices used in voltmeter setup to characterize the electrical properties of $\mathrm{SiO}_{x}$. After cleaning the substrates with high-performance liquid chromatography (HPLC) grade $\mathrm{CHCl}_{3}$ and blow-drying with $\mathrm{N}_{2}, 5 \mathrm{~nm}$ of chromium $(\mathrm{Cr})$ acting as an adhesion layer, followed by $50 \mathrm{~nm}$ of gold $(\mathrm{Au})$ were thermally evaporated in an evaporation chamber made by Thermionics TLI Enterprises, Inc. at a base pressure of $5 \times 10^{-6} \mathrm{mbar}$. Polymer semiconductor, PTDPPTFT4 (provided by Corning Incorporated), was dissolved within a glove box under a nitrogen atmosphere using a concentration of $c=5 \mathrm{mg} \mathrm{mL}^{-1}$ in HPLC grade chlorobenzene as received without further purification and deposited by spin-coating at $1000 \mathrm{rpm}$ for $1 \mathrm{~min}$ at $T=80^{\circ} \mathrm{C}$, after stirring overnight at $T=85^{\circ} \mathrm{C}$. All presented FET devices were built on common bottom-gate architecture and the polymer semiconductor was not patterned. The synthesis of PTDPPTFT4 was previously reported. ${ }^{[32]}$ After baking at $T=80^{\circ} \mathrm{C}$ for about $10 \mathrm{~min}$ under inert conditions, the semiconductor was transferred to a vacuum hotplate and vacuum annealed at $T=120^{\circ} \mathrm{C}$ for $2 \mathrm{~h}$ at a pressure of about $p \approx 50 \mathrm{mbar}$. $50 \mathrm{~nm}$ of $\mathrm{SiO}_{x}$ was thermally evaporated at a base pressure of $5 \times$ $10^{-6} \mathrm{mbar}$ and a rate of $0.5 \AA \mathrm{s}^{-1}$ using a Knudsen cell type boat and $\mathrm{SiO}$ pieces, purchased from Kurt J. Lesker Company with purity $99.9 \%$ as starting material. PDMS-based flow cells with a total volume of $V=170 \pm 5 \mathrm{~mm}^{3}$ were prepared from Sylgard 184 silicon elastomer kit from Dow Corning Co., (ratio of base to cross-linker of 10:1 by mass), using a mold and adding platinum (Pt) reference/ground electrodes. PBS $1 \times$ was prepared by using DI water, Milli-Q (MQ) quality with $\rho=18 \mathrm{M} \Omega \mathrm{cm}$, and phosphate-buffered saline tablets purchased from Sigma-Aldrich. $\mathrm{pH}$ levels of the electrolyte solutions were changed by adding hydrochloric acid $(\mathrm{HCl}) 37 \%$ or solid sodium hydroxide $(\mathrm{NaOH})$, both purchased from Sigma-Aldrich and used as obtained.
Electrical Characterization and Data Analysis: Electrical device characteristics were recorded using a setup including Keithley Source Meter, Model 2635A and Model 2400 with samples mounted within a metal Al box (Faraday cage) to stabilize temperature and minimize electrostatic noise at ambient conditions, $T=25 \pm 3{ }^{\circ} \mathrm{C}$ and relative humidity $(\mathrm{RH})=38-43 \%$. For the voltmeter setup, the Keithley $2635 \mathrm{~A}$ was set to high input impedance $\left(10^{14} \Omega\right)$ and the instrument ground was connected to the platinum electrode of the PDMS flow cell (continuous flow rate $=0.5 \mathrm{~mL} \mathrm{~min}^{-1}$ ). The electrical conductivity of all solutions was measured by using a handheld Ohaus

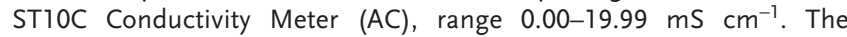
$\mathrm{pH}$ level of all solutions was measured by using a handheld Ohaus ST20 waterproofed $\mathrm{pH}$ meter, range $0.00-14 \mathrm{pH} ; 0.0-99.0{ }^{\circ} \mathrm{C}$ and measurement resolution $0.01 \mathrm{pH}$. $I_{\mathrm{D} \text {,ref }}$ was determined from the mean value of 25 point using PBS $1 \times$ with $\mathrm{pH} 7.4 \pm 0.1$ as reference. $I_{\mathrm{D}, \mathrm{pH}}$ was determined from the mean value of 25 point after stabilization and injection of the $\mathrm{pH}$ solution of interest. Sensor response was defined as: $\left(I_{\mathrm{D}, \mathrm{pH}}-I_{\mathrm{D}, \mathrm{ref}}\right) / I_{\mathrm{D}, \text { ref. }}$. Optical microscopy images were recorded with a cross-polarized optical microscope (Leica DM4000M). Thickness measurements were performed on a Dektak 150 profilometer (Veeco Metrology Group). Tapping mode atomic force microscopy was performed using a Multimode Nanoscope III (Digital Instruments/ Veeco Metrology Group). Electrical impedance spectra were measured using an Agilent E4980A Precision LCR meter (frequency range: $20 \mathrm{~Hz}-2 \mathrm{MHz}$ ), and gate capacitance values were measured and calculated for both $\mathrm{SiO}_{2}$ and $\mathrm{SiO}_{x}$ after thermal evaporation of $50 \mathrm{~nm}$ gold top electrodes in circular patterns $\left(A=0.1225 \pm 0.0001 \mathrm{~cm}^{2}\right)$. All remote measurements were carried out using homemade measurement routines and data analysis was done with MATLAB. All measurements were carried out at room temperature $T=25 \pm 3{ }^{\circ} \mathrm{C}$, after thermally stabilizing the solutions overnight to prevent temperature drift during the experiments. The setup was mounted within an Al measurement box, enabling electrostatic shielding.

\section{Supporting Information}

Supporting Information is available from the Wiley Online Library or from the author.

\section{Acknowledgements}

R.P. and A.M.F. contributed equally to this work. R.P. acknowledges support from the Marie Curie Cofund, Beatriu de Pinós Fellowship (AGAUR 2014 BP-A 00094). A.M.F. acknowledges a postdoctoral fellowship support from the Natural Sciences and Engineering Research Council (NSERC) of Canada. This project was supported by the Stanford Catalyst for Collaborative Solutions Program and the Beijing Institute of Collaborative Innovation (BICl).

\section{Conflict of Interest}

The authors declare no conflict of interest.

\section{Keywords}

dual-gate organic field-effect transistors, $\mathrm{pH}$ sensors, silicon monoxide, tunable sensitivity

Received: June 16, 2018

Revised: October 13, 2018

Published online: November 22, 2018 
[1] S. P. L. Sørensen, Biochem. Z. 1909, 21, 131.

[2] D. A. MacInnes, M. Dole, Ind. Eng. Chem., Anal. Ed. 1929, 1, 57.

[3] A. O. Beckman, US2058761, 1936.

[4] M. Yuqing, C. Jianrong, F. Keming, J. Biochem. Biophys. Methods 2005, 63, 1

[5] P. Bergveld, IEEE Trans. Biomed. Eng. 1970, BME-17, 70.

[6] Y. Cui, Q. Wei, H. Park, C. M. Lieber, Science 2001, 293, 1289.

[7] R. Sivakumarasamy, R. Hartkamp, B. Siboulet, J. F. Dufrêche, K. Nishiguchi, A. Fujiwara, N. Clément, Nat. Mater. 2018, 17, 464.

[8] M. H. Lee, B. J. Kim, K. H. Lee, I.-S. Shin, W. Huh, J. H. Cho, M. S. Kang, Nanoscale 2015, 7, 7540

[9] W. Fu, C. Nef, O. Knopfmacher, A. Tarasov, M. Weiss, M. Calame, C. Schönenberger, Nano Lett. 2011, 11, 3597.

[10] M. E. Roberts, S. C. B. Mannsfeld, N. Queraltó, C. Reese, J. Locklin, W. Knoll, Z. Bao, Proc. Natl. Acad. Sci. USA 2008, 105, 12134.

[11] R. Giridharagopal, L. Q. Flagg, J. S. Harrison, M. E. Ziffer, J. Onorato, C. K. Luscombe, D. S. Ginger, Nat. Mater. 2017, 16, 737.

[12] H. S. White, G. P. Kittlesen, M. S. Wrighton, J. Am. Chem. Soc. 1984, 106, 5375 .

[13] G. Scheiblin, R. Coppard, R. M. Owens, P. Mailley, G. G. Malliaras, Adv. Mater. Technol. 2017, 2, 1600141.

[14] L. Kergoat, L. Herlogsson, D. Braga, B. Piro, M.-C. Pham, X. Crispin, M. Berggren, G. Horowitz, Adv. Mater. 2010, 22, 2565

[15] J. Kofler, K. Schmoltner, A. Klug, E. J. W. List-Kratochvil, Appl. Phys. Lett. 2014, 104, 193305.

[16] M.-J. Spijkman, J. J. Brondijk, T. C. T. Geuns, E. C. P. Smits, T. Cramer, F. Zerbetto, P. Stoliar, F. Biscarini, P. W. M. Blom, D. M. de Leeuw, Adv. Funct. Mater. 2010, 20, 898.

[17] A. Spanu, F. Viola, S. Lai, P. Cosseddu, P. C. Ricci, A. Bonfiglio, Org. Electron. 2017, 48, 188

[18] H. N. Al-Hardan, A. M. Abdul Hamid, M. N. Ahmed, A. Jalar, R. Shamsudin, K. N. Othman, L. Kar Keng, W. Chiu, N. H. Al-Rawi, Sensors 2016, 16, 1

[19] H. Guliga, W. F. H. Abdullah, S. H. Herman, in 2014 2nd Int. Conf. on Electrical, Electronics and System Engineering (ICEESE), IEEE, Kuala Lumpur, Malaysia 2014, pp. 11-14.

[20] L. Yu-Ren, C. Shih-Hsueh, C. Chia-Tsung, T. Wan-Lin, C. Yu-Kai, Y. Po-Yu, C. Huang-Chung, Jpn. J. Appl. Phys. 2016, 55, 04 EM08.

[21] J. Kim, J. Jang, K. Kim, H. Kim, S. H. Kim, C. E. Park, Adv. Mater. 2014, 26, 7241.

[22] C. Wang, W.-Y. Lee, D. Kong, R. Pfattner, G. Schweicher, R. Nakajima, C. Lu, J. Mei, T. H. Lee, H.-C. Wu, J. Lopez, Y. Diao, X. Gu, S. Himmelberger, W. Niu, J. R. Matthews, M. He, A. Salleo, Y. Nishi, Z. Bao, Sci. Rep. 2016, 5, 17849.

[23] F. G. del Pozo, S. Fabiano, R. Pfattner, S. Georgakopoulos, S. Galindo, X. Liu, S. Braun, M. Fahlman, J. Veciana, C. Rovira, X. Crispin, M. Berggren, M. Mas-Torrent, Adv. Funct. Mater. 2016, 26, 2379

[24] M. Nikolka, I. Nasrallah, B. Rose, M. K. Ravva, K. Broch, A. Sadhanala, D. Harkin, J. Charmet, M. Hurhangee, A. Brown, S. Illig, P. Too, J. Jongman, I. McCulloch, J.-L. Bredas, H. Sirringhaus, Nat. Mater. 2017, 16, 356.

[25] T. Lei, M. Guan, J. Liu, H.-C. Lin, R. Pfattner, L. Shaw, A. F. McGuire, T.-C. Huang, L. Shao, K.-T. Cheng, J. B.-H. Tok, Z. Bao, Proc. Natl. Acad. Sci. USA 2017, 114, 5107.

[26] G. A. Thibodeau, K. T. Patton, Structure \& Function of the Body, Elsevier, St. Louis, MO 2012.

[27] J. A. Kellum, Crit. Care 2000, 4, 6.

[28] F. Herrmann, L. Mandol, J. Invest. Dermatol. 1955, 24, 225.
[29] V. E. Bower, M. Paabo, R. G. Bates, J. Res. Natl. Bur. Stand., Sect. A 1961, 65A, 267.

[30] V. Srinivasan, V. K. Pamula, R. B. Fair, Lab Chip 2004, 4, 310.

[31] W.-Y. Lee, G. Giri, Y. Diao, C. J. Tassone, J. R. Matthews, M. L. Sorensen, S. C. B. Mannsfeld, W.-C. Chen, H. H. Fong, J. B. H. Tok, M. F. Toney, M. He, Z. Bao, Adv. Funct. Mater. 2014, 24, 3524.

[32] J. R. Matthews, W. Niu, A. Tandia, A. L. Wallace, J. Hu, W.-Y. Lee, G. Giri, S. C. B. Mannsfeld, Y. Xie, S. Cai, H. H. Fong, Z. Bao, M. He, Chem. Mater. 2013, 25, 782.

[33] D. Hubbard, J. Res. Natl. Bur. Stand. 1946, 36, 511.

[34] G. Hass, C. D. Salzberg, J. Opt. Soc. Am. 1954, 44, 181.

[35] C. R. Helms, B. E. Deal, The Physics and Chemistry of $\mathrm{SiO}_{2}$ and the Si-SiO 2 Interface, Prenum, New York, NY 1988.

[36] K. W. Wecht, Appl. Opt. 1991, 30, 4133.

[37] J. Zaumseil, H. Sirringhaus, Chem. Rev. 2007, 107, 1296.

[38] L.-L. Chua, J. Zaumseil, J.-F. Chang, E. C. W. Ou, P. K. H. Ho, H. Sirringhaus, R. H. Friend, Nature 2005, 434, 194.

[39] P. Jutzi, U. Schubert, Silicon Chemistry: From the Atom to Extended Systems, Wiley-VCH Verlag GmbH \& Co. KGaA, Weinheim 2003

[40] A. Hohl, T. Wieder, P. A. van Aken, T. E. Weirich, G. Denninger, M. Vidal, S. Oswald, C. Deneke, J. Mayer, H. Fuess, J. Non-Cryst. Solids 2003, 320, 255

[41] B. Friede, M. Jansen, J. Non-Cryst. Solids 1996, 204, 202.

[42] Y. Baba, T. Sekiguchi, I. Shimoyama, N. Hirao, Surf. Sci. 2013, 612, 77.

[43] T. P. Nguyen, S. Lefrant, J. Phys.: Condens. Matter 1989, 1, 5197.

[44] Y. G. Bérubé, P. L. de Bruyn, J. Colloid Interface Sci. 1968, 28, 92

[45] Y. G. Bérubé, P. L. de Bruyn, J. Colloid Interface Sci. 1968, 27, 305.

[46] H. Wright, R. Hunter, Aust. J. Chem. 1973, 26, 1183.

[47] D. E. Yates, S. Levine, T. W. Healy, J. Chem. Soc., Faraday Trans. 1 1974, 70, 1807

[48] P. R. Barabash, R. S. C. Cobbold, IEEE Trans. Electron Devices 1982, 29, 102.

[49] A. S. Feiner, A. J. McEvoy, J. Chem. Educ. 1994, 71, 493.

[50] R. E. G. van Hal, J. C. T. Eijkel, P. Bergveld, Adv. Colloid Interface Sci. 1996, 69, 31.

[51] D. Hubbard, M. H. Black, G. F. Rynders, J. Res. Natl. Bur. Stand. $1950,45,430$.

[52] S. Iba, T. Sekitani, Y. Kato, T. Someya, H. Kawaguchi, M. Takamiya, T. Sakurai, S. Takagi, Appl. Phys. Lett. 2005, 87, 023509.

[53] M.-J. Spijkman, K. Myny, E. C. P. Smits, P. Heremans, P. W. M. Blom, D. M. de Leeuw, Adv. Mater. 2011, 23, 3231.

[54] F. Maddalena, M. Spijkman, J. J. Brondijk, P. Fonteijn, F. Brouwer, J. C. Hummelen, D. M. de Leeuw, P. W. M. Blom, B. de Boer, Org. Electron. 2008, 9, 839

[55] Y. M. Park, A. Salleo, Appl. Phys. Lett. 2009, 95, 133307.

[56] L. Yang, H. Wang, X. Zhang, Y. Li, X. Chen, X. Xu, X. Zhao, A. Song, IEEE Trans. Electron Devices 2017, 64, 1846

[57] M. Yun, A. Sharma, C. Fuentes-Hernandez, D. K. Hwang, A. Dindar, S. Singh, S. Choi, B. Kippelen, ACS Appl. Mater. Interfaces 2014, 6, 1616.

[58] R. Pfattner, M. Foudeh Amir, C. Liong, L. Bettinson, C. Hinckley Allison, D. Kong, Z. Bao, Adv. Electron. Mater. 2018, 4, 1700326.

[59] M. Spijkman, E. C. P. Smits, J. F. M. Cillessen, F. Biscarini, P. W. M. Blom, D. M. de Leeuw, Appl. Phys. Lett. 2011, 98, 043502.

[60] M. G. Nikolaides, S. Rauschenbach, A. R. Bausch, J. Appl. Phys. 2004, 95, 3811. 